EGU2020-8936

https://doi.org/10.5194/egusphere-egu2020-8936

EGU General Assembly 2020

(c) Author(s) 2021. This work is distributed under

the Creative Commons Attribution 4.0 License.

\title{
Network scale sediment connectivity to explore stability and resilience of channel forms and river types in the Vjosa basin
}

\author{
Marco Tangi ${ }^{1}$, Simone Bizzi ${ }^{2}$, and Andrea Castelletti ${ }^{1}$ \\ ${ }^{1}$ Department of Electronics, Information, and Bioengineering, Politecnico di Milano, Milan, Italy (marco.tangi@polimi.it) \\ ${ }^{2}$ Department of Geosciences, Università di Padova, Padua, Italy
}

Sediment connectivity is a fundamental property of river network, which directly influences the geomorphological processes regulating the formation and development of the different in-channel geomorphic units and leading to different river types. Alterations of sediment connectivity, e.g. caused by human disturbances such as dam construction or bed mining, are often followed by changes in channel patterns resulting in potential radical shifts in river types, e.g., from braided systems to sinuous single channel, with consequent loss of river ecosystems associated with specific river types.

In this work, we analyze the connections between basin-scale sediment connectivity indices and river types with the aim of advancing our quantitative ability to inter-relate channel forms and processes with type and amount of sediment fluxes available to the river channel. Our study focuses on the Vjosa river, Albania, which due to the limited anthropogenic bias still showcases a large variety of fluvial forms, including ample sections of braided channels, some of the few remaining in Europe and well renewed as ecological hotspots. The Vjosa river is now interested by large scale hydropower development plans, which may threaten the river unique ecological and morphological value. We estimate sediment transport using the CASCADE model, a modelling framework for basin-scale sediment transport simulation, which generates spatially distributed information on sediment movement and connectivity in river networks. The model has been validated using available data on bed load transport in a braided section close to the basin outlet and surficial grain size distributions collected across the river network.

By integrating CASCADE outputs (i.e., sediment fluxes and size distributions) with available geomorphic information at the network scale (e.g., channel slope and water discharge), we successfully tested an empirical formula proposed in literature based on sediment concentration, median grain size, channel slope and bankfull discharge, to disentangle the drivers of braided or single channel patterns. We then tested the same threshold for different dam development portfolios, showing how even few new dams would alter current conditions in terms of type and amount of sediment availability, leading to multiple channel type shifts from braided to sinuous single channel across the network.

For the first time, the incorporation of the CASCADE model with more traditional geomorphic analysis of river system demonstrate how CASCADE sediment connectivity information advances 
our ability to interpret existing river system processes, to assess stability of the different channel forms and to evaluate resilience and identify tipping points of fragile system like the Vjosa basin. 